\title{
Omani Women: Embracing New Identity
}

\author{
Najwa Abd Ghafar \\ Universiti Teknologi Malaysia, Malaysia \\ najwa_g@hotmail.com
}

\section{Doi:10.5901/ajis.2013.v2n8p470}

\begin{abstract}
Like other women around the world, Omani women have always worked. In the past, they worked along their men, tending the herds, and bargaining at cattle souks. Now women are still working, but the nature of work has changed over time with the modernization and material aspiration. This qualitative study explores the perception of Omani professional women on being working and its association with their identity. Data from interviews and printed media revealed that being professional serves as means not only to meet ends but also to actualize self by embracing multiple roles.
\end{abstract}

\section{Identity Theory}

Identity is defined as meaning an individual attributes to one's self in a role (Burke and Reitzes, 1981). Burke and Reitzes (1981) suggested that this definition infers three characteristics. First, identities are social products, where they are formed and maintained through social process. Second, identities are organized in hierarchy to produce the self; and third, identities are reflexive in character in the sense that people internalize an identity from responses of others upon performing their identity role.

One of the major discussions in identity theories is identity salience. This identity salience can be internalized and become a stable part of self or be an unstable one and changes to fit changing situation (Owens et al., 2010). As people tend to have multiple roles, they tend to have multiple identities which are organised into hierarchy according to degree of salience. Based on this it can be understood that professional women with children may arranged their multiple roles - i.e. professional woman, mother, neighbour, friend etc. into hierarchy.

Social identity theorists argue that identity is a social-construct, as it is constructed through interaction with other members in a society (Owen et al., 2010; Turner, 2013). An identity is reinforced and enacted as one engages in activities, and interacts with others in the environment (Bird and Schnurmann-Crook, 2005). Through interaction and engagement, people develop self-approval and seek approval of significant others in determining whether an identity intended to embrace is approved, and subsequently determining the position of the identity within the hierarchy of salience (ibid. p.146).

As such culture strongly influences how pyramid of salient identity looks like by prescribing priorities in life (Aycan et al., 2005). Society also influences whether two identities are compatible or contesting (Rothbard and Edwards, 2003). If they are perceived incompatible, the less important one will be less committed to or - when threatened, will be sacrificed at once. In many countries around the world, careers that are related to caretaking, nurturing, and entertaining are deemed compatible to women's nature as emotional and sensitive.

Work-family literature reveals that home culture and work culture determine work-family experience. Supportive husbands, who share house chores, take turn to take leaves to attend children's school program, encourage wife to take up job assignment for promotion, help women to balance their domestic and professional roles. Supportive work culture in the form of supportive colleagues, understanding bosses, flexible work hour also provide an encouraging environment for women to perceive themselves as part of organisation and be committed to their career development. Subsequently balanced work-family roles enable women to maintain their domestic identity as well as retaining their professional identity.

\section{Omani Professional Women}

Among Arab patriarchy countries, Oman has constantly been described as the most flexible and tolerant in many aspects. Although gender-based identity is well-defined, gender-based household division is rather implicit and flexible (Al-Barwani and Albeely, 2007). Children are tended by both father and mother often with the help of extended family 
members. Although women are the cook at home, men do cook when necessary. The rising of dual-earner families where both husband and wife work and earn money for family therefore do not pose any drastic change in this society. As such it is not a surprise when Oman was categorised as the least masculine society (At-Twaijiri and Al-Muhaiza, 1996).

Hofstede (1980) described that the dominant values for a high masculine country are success, money and things while the dominant values for a low masculine (or feminine) country are caring for others, and the quality of life, and people. While masculinity is associated with work prevails over family, femininity is associated with balance between family and work (Hofstede, 2011). Given this characteristic one might simply conclude that Omani society does not have any issue having their women working, and balance between home and work can easily be attained. However, the reality uncovers the opposite.

An official government report revealed a significant premature withdrawal from work among young Omani women professionals (MONE, 2011). Data in 2010 showed close to 50 per cent of female workforce between the ages 25 and 29 withdrew from work. As Omani women get married at the average age of 26, it explains their withdrawal as they reach 30 's of age, which coincides with the timing when the family is growing. The report also revealed lack of facilities in the workplace as the factor of the retreat. This concurs with the findings by Bird and Schnurman-Crook (2005) that absence of facilities and family-friendly policies does hamper the development of professional identity.

Omani society therefore, is conservative at heart (Peterson, 2011). Men are regarded as the main breadwinner, and are responsible to go outside i.e. earning income, and providing house to live, and clothes and food for family. Women are in-charged of domestic matter i.e. providing home, preparing food and cleaning. Even when there is maid, it is women's area to liaise with the maid for house chores. In Omani family, father/husband is the most powerful figure. Women are consulted, and their opinion matters; but the last say is always men's (AlBarwani and Albeely, 2007). Men decide whether or not women should continue study, whether they should work, and what type of job and career they should and can have home (Al-'Omairi and Amzat, 2012).

To date, some Omani men still believe that women's place is at home (Al-'Omairi and Amzat, 2012) and to most Omani women their family identity (defined by Bird and Schnurman-Cook, 2005 as 'a combination of spousal and parental identities') is at the top of their identity hierarchy. Chatty (2000) wrote, 'In Omani society, as in the modern nation-states of the Middle East, ... women are perceived first and foremost as wives and mothers (p. 247). As such, wife and mother are the most salient identities in the identity hierarchy of Omani professional women. Any other identities especially when they are non-domestic are considered secondary and in some cases are considered a threat (Bird and Schnuman-Cook, 2005).

Being mothers and wives means they are expected to spend time most of the time at home. Jobs that require them staying outside home and away from family for long time are considered unsuitable for women. Although there is indication that younger women started not to limit their career options, in general women are still drawn to teaching and administrative positions. The arrangement of 7-8 hours a day and five days a week is considered ideal for women to balance their domestic and professional roles. Long working hours and jobs away from home are considered threatening women's identity as wife and mother. Embracing the identity as professional woman therefore does not happen without challenge.

\section{Significance of the Study}

The study is significant for at least two reasons: First, Omani government is aiming to double their women's participation in the national workforce by the year 2020 (MONE, 2010). Knowing how the society at large perceives women as professionals gives the clue whether it is a smooth process or not. Second, it shed lights to many issues faced by Omani professional women. By understanding their self-perceived identity, one can understand their commitment and strategy to attain balance between family and profession.

\section{Research Strategy}

This qualitative study has explored the perception of Omani professional women on being working and its association with their identity from identity theory perspective. This research borrowed ethnographic strategy considering its orientation towards cultural interpretation. Culture provides system of meaning that constructs social arrangements including life options for men and women (Bradley and Kor, 1993). As such, the research explored how Omani women embrace and construct their identity within the context of Omani culture. 


\section{Research Method}

Investigation was carried out by conducting series of interview and collecting printed media articles. Ethnographic interviewing is distinct from non-ethnographic interviewing in the sense that it is more of 'series of friendly conversation' (Spradley, 1979, cited in Sorrell and Redmond, 1995). This friendly conversation often happens unarranged and spontaneous, thus deemed to provide more realistic account compared to information gathered from formal interview (Murchison, 2010). As such not all interviews were tape-recorded. However, to assure reliability, field notes were taken as soon as the conversation ended. This paper and pencil note-taking also was done in order not to discourage spontaneity and honesty from the research participants.

The second method is document and image analyses where local magazines and national newspaper will be the source of information. Among them are $Y$ magazine, Oman Economic Review, Times of Oman, and Oman Observer newspapers. These magazines and newspaper portray current situation of Omani society which illuminates differences from the past situation. Coverage on achievement of Omani women in these printed media provides excellent description of identity of Omani professional women, as well as identity which Omani women aspired to become.

While interview provides powerful testimonials, visual data, as argued by Razvi (2006) have the potential to support and corroborate narratives. More importantly, images which are captured in cultural setting offer not only unique, but also authentic description of the phenomenon under study. Combining these two tools i.e. interview and document/image analyses is deemed to better able capture as comprehensive as possible the identity subscribed by Omani professionals, and prescribed by the society.

\subsection{Participants}

Sampling was selected purposely. Two participants were acquaintances to the researcher. They later suggested other participants. Some of the participants also were those the researcher met at shopping complex, dental clinic, and hospital.

\subsection{Data Collection}

Nine participants were interviewed. Face-to-face interview was done with seven participants, taking place at either the researcher's place, or the participants' workplaces. Four of them were lecturers at higher education, three were school teachers and one is a salesperson. Telephone interview was done with two participants due to their time constraint. One was salesperson, and another was an assistant at dental clinic. Both types of interview were open-ended and semistructured. Among these participants, five of them were married with children, one was married without child, and three were not married.

The interviews were conducted in English. It was not the researcher's intention to limit the study only to those who were able to speak English. However, those who did speak, or willing to speak English were more approachable and cooperative, compared to those who did not speak the language.

\subsubsection{Interview question}

1. How do you feel being a working/professional woman?

\subsubsection{Probing questions}

1. Can you describe your feelings about being a professional woman?

2. Does your family encourage you to work? What does your husband think about you working?

3. Is there any pressure for you to stop working?

4. If your family asks you to stop working, would you so?

5. Can you imagine yourself being unemployed?

6. Overall speaking are you satisfied/proud that you are working? 


\section{Analysis}

The researcher utilized descriptive and ethnographic content analysis to analyse, describe, and summarize the collected data. Recorded interviews were transcribed, while field notes on the non-recorded interviews were analysed in order to derive themes.

\section{Result and Discussion}

Several themes were yielded from the interviews as well from the published media articles in regards to Omani women professional identity.

\subsection{Domestic identity is the most salient in the hierarchy.}

Domestic identity takes priority over other identities. To some, working in fact is part of being mother and wife, where they help their husbands by earning extra income for the family. A school teacher for example expressed,

Now everything is expensive. Of course there are cheap and expensive stuffs. But at least if a wife is working, they [the family] have money to provide quality goods to the children....Not everybody can get to go to university. So if both parents work, at least they can send their children to private universities and colleges.

\subsection{Professional identity is a meaningful identity.}

Many Omani women, irrespective of levels of education perceive career as enriching and professional identity as important to them. One of the lecturers uttered,

I can't imagine myself stop working. To me, I am Noor, an English teacher. That's what I do. My child [is] first [priority]...[I am a mother] but that's not all I am.

Haniah, a salesperson at high-end boutique in Muscat City Center with high school certificate shared,

I love working. It makes me know who I am. I love meeting people. I like to try to speak English. If I sit at home I might get involve in wrong thing, or I will feel bored.

In a group interview with three participants, they agreed that by being working their opinions matter more to their families. They were consulted for major purchases like cars and lands, and their advices were sought as to which college their younger siblings should be attending.

\subsection{Family support is important in developing and embracing professional identity.}

Many of the participants receive moral support from family, in fulfilling their responsibilities as mothers and working women. They live with their mother or mother-in-law who looks after their children when they are at work. From the participants, the researcher learnt that many Omani families understand when their daughters have to stay back at workplace to do extra workload. Fatimah, another salesperson with two children said that she was grateful her mother never complained when she had to work for long hours. Many days a week she left home at 9 a.m to arrive at work by 9.30 a.m. and stayed until 6 p.m. She confessed never worried about her children as they are in safe hands.

\subsection{Husband's approval is a factor of success in professions.}

Approval from husband is crucial in determining the course of Omani women's professions. Almost all married participants attribute their ability to juggle between domestic and professional identities to their husbands. Thuraiyya, a school teacher expressed her content to have a husband who is also a school teacher. She said they always talked about issues pertaining students and education. She expressed her wish to further study and teach in higher education, but concerned about having to teach in co-educational institution. Her husband did not mind of her intention to further study but discouraged her from working in mixed-gender environment.

Many Omani working women perceived that husband's approval of their career as significant. Many of them 
expressed that they love their work but will stop working if their husband ask them to. Conforming to the husband's will is regarded as sign of love and obedience.

\subsection{Husband sharing domestic chores helps in retaining professions.}

Husbands' understanding and willingness to share household tasks are strength for professional women to keep their professional identity. Aseelah, a retiring school teacher with 5 children had been working for 20 years. Her husband had always helped with house chores like cooking and washing dishes, especially at times when they did not have maid. Noor, whose first baby was 5 months at the time of interview, expressed her gratitude for having a supportive husband. Her husband worked in the dessert and in a month, he worked for two weeks and stayed at home for another two weeks. During his stay, he would take care of the baby while Noor teaching in the college 70 kilometers from their home.

\subsection{Organizational support is a motivation for retention of professional identity.}

Support at workplace motivates commitment to profession as it enables balance between work and family. Aseela had a maid at home. However, sometimes it took time to get new maid when the previous one finished her contract. In this kind of situation, she always had to leave school early so she can cook and be at home when her children come back from school. Her head department and colleagues understood her situation and never complained of her early leaving as long as she informed them of the situation.

In general media in Oman highlights positive pictures of professional women. Their involvement in the workforce has repetitively been stressed in many printed media articles. Columnists in Oman Daily Observer newspaper like alBalushi (18 $8^{\text {th }}$ February, 2013) and al-Suleimany $\left(6^{\text {th }}\right.$ June, 2013) acknowledged the importance of women's participation in the workforce. Al-Balushi wrote,

Today you hardly observe a shop, a mall medical centre, bank, insurance company, business, hotel, institute, education centre, sports, police and army without women. It means that women are playing a great part in building the state and its economy, with their hard work, creativity, innovation and co-operation. (p.27)

Omani professional women were portrayed as vibrant and ambitious personalities. It is noteworthy however that as being successful mothers is important to this society, very often professional women are portrayed as successful both as mothers and professionals. Y-Magazine (Issue 260) for example published two articles of such story. One is coverage on a managing director whose ultimate ambition is to be 'the one-of-a-kind type of mother' (p.6), and another is on a business analyst, who is also a mother of two, in preparation for an International Antarctic Expedition. The column in which story on her was published printed with the title 'The Adventurer (and Mum)' (p.16). The success of a woman therefore is measured by her success in living up to her domestic identity. No matter how successful she is professionally, what validate her success is her success as wife and mother.

Although the atmosphere for Omani women as professionals is generally positive, there are some reservations against it. Some doubt on the motive of their employment in their first place. An Omani husband (Oman Daily Observer, $19^{\text {th }}$ April, 2011) for example said, 'By her working she relieves me of some costs like her cosmetics and household item' (p.26). Although women professionalism is no longer strange, women are still expected to devote themselves to domestic traditional identity. 


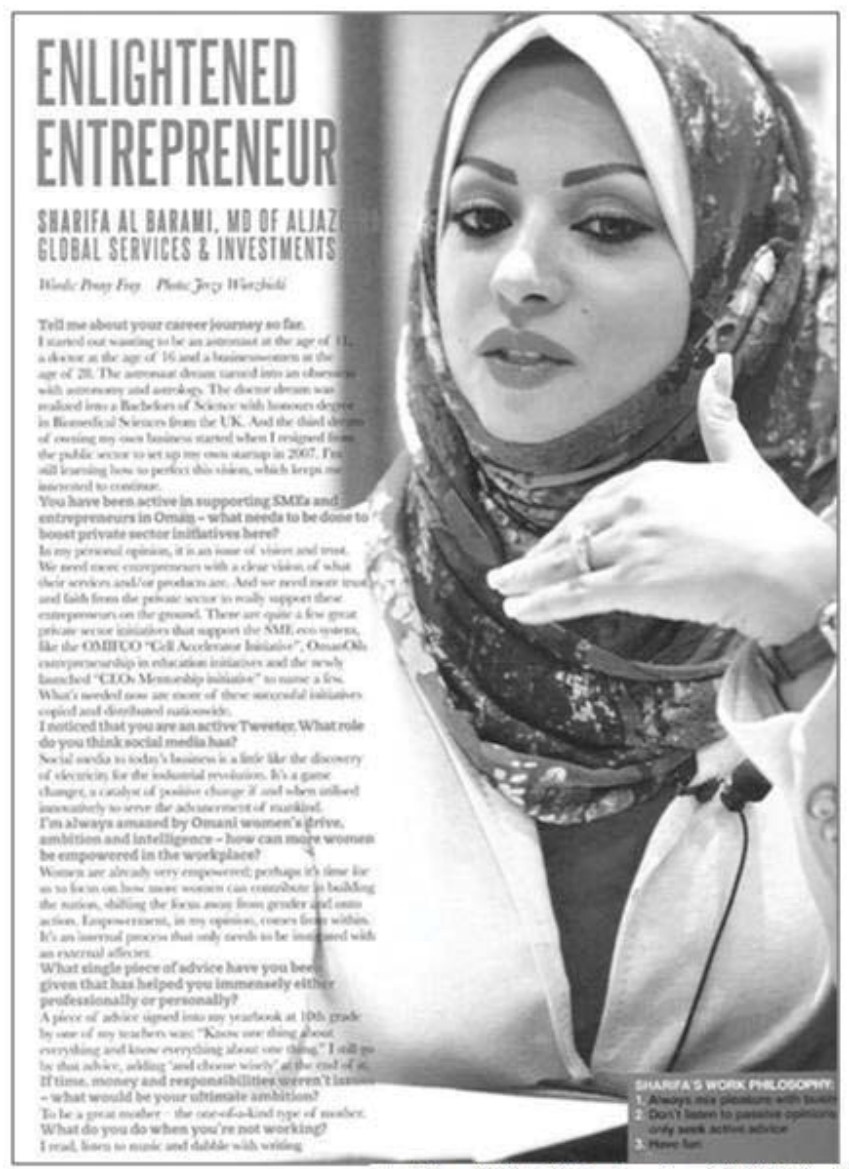

Article credited to Y Magazine, Is sue 260 (2013), p.6

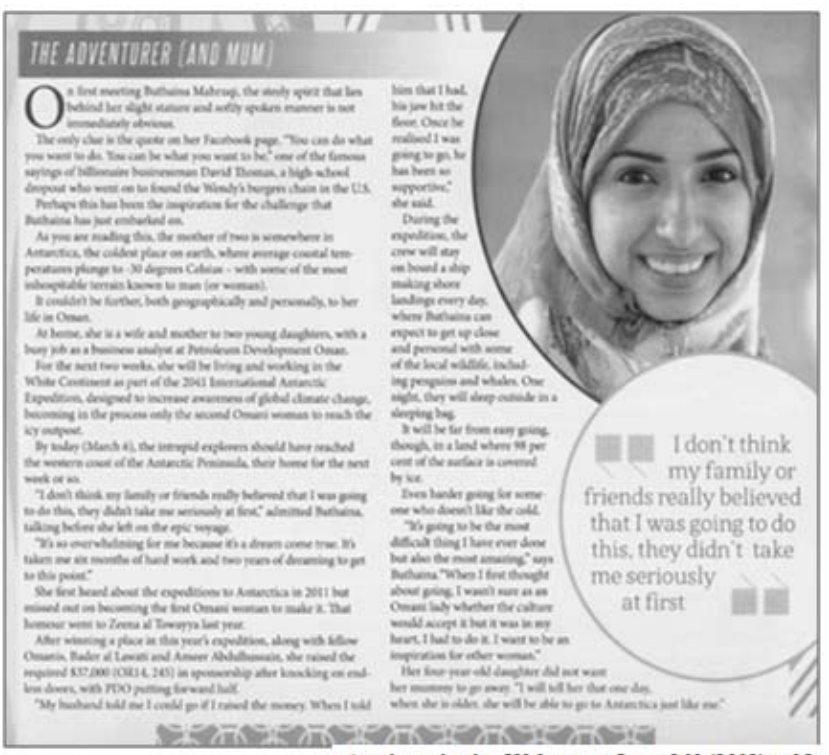

Article credited to Y Magazine, Is sue 260 (2013), p.19 
They are wives and mothers who are expected to do the daily chores and expecting husbands to share the chores at full scale is considered unacceptable. A columnist in Oman Daily Observer (7th May, 2013) wrote:

If you have allowed the women to have the wings and go to where they have never been, then the men will have to do the house works and should not care if they are called 'lesser men' or 'inferior'. (p.31)

He further warned the society that allowing women 'to go extra miles' might defy the traditional husband-wife identity. He asserted:

The rise of the modern career woman will cause disastrous effects on many husbands who assume the traditional 'female' role hence the need to initiate some action points. If the women becomes 'too big headed' over their husbands, don't blame them or anyone because you allowed it to start. (p.31)

For a woman therefore her professional identity is approved as long as it is not at conflict with her domestic identity, and it does not pose threat to her husband's identity as the prime breadwinner and head of the family.

\section{Limitation of the study}

The researcher views that it is important to note that interviews were conducted only with participants who were able to speak English. Analysis on media articles also was done on magazines and newspaper published in English. As such this study is limited. Perhaps, better understanding can be grasped if study was covering Arabic materials, and interview was conducted with Arabic-speaking participants.

\section{Conclusion}

It can be concluded that there is an ambivalent experience as well as reaction towards Omani women as professionals. They are partly celebrated, yet partly frowned upon either. What clear is, Omani women are slowly acknowledging their contribution to their family and society by being professionals.

\section{References}

Al-'Omairi, T. and Amzat, I.H. (2012). Women in Omani Society: Education and Participation. International Journal of Sustainable Development. 3(5), 63-80.

Al-Barwani, T. A., and Albeely, T.S. (2007). The Omani Family: Strengths and Challenges. Marriage and Family Review. 41(1-2), 119142.

Al-Balushi, M. (18th February, 2013). Women's Role in Boosting Nation's Economy. Oman Daily Observer. P.27.

Al-Musalmy, N. (19th April, 2011). Working Women. Oman Daily Observer. Retrieved 15th December, 2011, from http://main.omanobserver.om/node/47879

Al-Musalmy, N. (7th May, 2013). The Househusband. Oman Daily Observer. P.31.

Al-Suleimany, M. (6th June, 2013). Working Women. Oman Daily Observer. P.31.

At-Twaijiri, M.I. and Al-Muhaiza, I.A. (1996). Hofstede's Cultural Dimensions in the GCC Countries: An Empirical Investigation. International Journal of Value-based Management. 9, 121-131.

Aycan, Z. (2005). Cross-cultural Approaches to Work-family Conflict. Paper presented at Conference on Work and Family Interface, Barcelone, Spain. Retrieved 2nd January 2011 from http://www.workfamilyconflict.ca/cms/.../47/cc_wfc_chapter_-_finalized.doc

Bird, G.W. and Schnurman-Cook, A. (2005). Professional Identity and Coping Behaviors in Dual-Career Couples. Family Relations.

Bradley, K.and Khor, D. (1993). Toward an integration of theory and research on the status of women. Gender and Society. 7(3), 347378.

Brook, A.T., Garcia, J., and Fleming, M. (2008). The Effects of Multiple Identities on Psychological Well-Being. PSPB. 34(12), 15881600.

Burke, P.J. and Reitzes, D.C. (1981). The Link between Identity and Role Performance. Social Psychology Quarterly. 44(2), 83-92.

Chatty, D. (2000). Women Working in Oman: Individual Choice and Cultural Constraints. International Journal of Middle East Studies. 32: 241-254.

Hofstede, G. (2011). Dimensionalizing Cultures: The Hofstede Model in Context. Online Readings in Psychology and Culture. Retrieved from http://scholarworks.gvsu.edu/orpc/vol2/iss1/8

Hofstede, G. (1980). Culture's Consequences: International Differences in Work-Related Values. Beverly Hills CA: Sage Publications.

Hofstede, G. (2011). Dimensionalizing Cultures: The Hofstede Model in Context. Online Readings in Psychology and Culture. Retrieved from http://scholarworks.gvsu.edu/orpc/vol2/iss1/8 
Ministry of National Economy, Oman. (2010). 40 Glorious Year: 1970-2010. Retrieved 12th February, 2011 from http://www.mone.gov.om/PublicationAttachment/40e.pdf

Ministry of National Economy, Oman. (2011). Omani Women in the Labor Market and the Challenges They Face (Arabic). Retrieved 8th January, 2012 from http://www.mone.gov.om/PublicationAttachment/WOMAN\%20AT\%20WORK.pdf

Murchison, J.M. (2010). Ethnography Essentials. California: John Wiley and Sons, Inc.

Owens, T.J., Robinson, D.T., and Smith-Lovin, L. (2010). Three Faces of Identity. Annual Review of Sociology. 36, 477-499.

Peterson, J.E. (2011). Oman Faces the Twenty-first Century in Tétreault, M. Okruhlik, G., and Kapiszewski, A. (eds) Political Change in the Arab Gulf States. London: Lynne Rienner Publishers. Retrieved 18th December, 2011 from www.jepeterson.net/sitebuildercontent/sitebuilderfiles/Peterson_Oman_Faces_21st_Century.pdf.

Razvi, M. (2006). Image-based Research: Ethics of Photographic Evidence in Qualitative Research. Paper presented at the Midwest Research-to-Practice Conference in Adult, Continuing, and Community Education, University of Missouri-St. Louis, St. Louis. Retrieved 23rd February, 2013 from http://www.umsl.edu/continuinged/education/mwr2p06/pdfs/D/Razvi_ImageBased_Research.pdf

Rothbard, N.P. and Edwards, J.R. (2003). Investment in Work and Family Roles: A Test of Identity and Utilitarian Motives. Personnel Psychology. 56(3), 699-729.

Sorrell, J.M. and Redmond, G.M. (1995). Interviews in Qualitative Nursing Research: Differing Approaches for Ethnographic and Phenomenological Studies. Journal of Advanced Nursing. 21, p. 1117-1122.

Turner, J.H. (2013). Contemporary Sociological Theory. U.S.: Sage Publications, Inc. 